Article

\title{
An Incentive Factor-Based Dynamic Comprehensive Evaluation on a High-Speed Railway Track
}

\author{
Xiaohui Wang ${ }^{1,2}$, Jianwei Yang ${ }^{2, *}$, Jinhai Wang ${ }^{2}$, Yanxue Wang ${ }^{2}$, and Guiyang $\mathrm{Xu}^{2}$ \\ 1 School of Civil and Transportation Engineering, Beijing University of Civil Engineering and Architecture, \\ Beijing 100044,China; wangxiaohui@stu.bucea.edu.cn \\ 2 Beijing Key Laboratory of Performance Guarantee on Urban Rail Transit Vehicles, Beijing University of Civil \\ Engineering and Architecture, Beijing 100044, China; wangjinhai@bucea.edu.cn (J.W.); \\ yan.xue.wang@gmail.com (Y.W.); xuguiyang@bucea.edu.cn (G.X.) \\ * Correspondence: yangjianwei@bucea.edu.cn
}

Received: 26 June 2020; Accepted: 7 August 2020; Published: 11 August 2020

check for updates

\begin{abstract}
Peak management and mean management are common ways to manage the quality of high-speed railway tracks at present. The most popular method for evaluating such tracks is the track quality index (TQI) method, which can reflect the overall state of the equipment to a certain extent. However, this method is likely to ignore some potential risks that threaten the operation of a high-speed train. For more effective risk identification, an incentive factor-based dynamic comprehensive evaluation (DCE) method was introduced to assess the geometric parameters of a high-speed railway track. Moreover, the weights of geometric parameters were computed by a combination of the analytic hierarchy process (AHP) and entropy based on the correlation coefficient. The proposed method can highlight the sensitivity index of the geometric parameters, which is an advantage over the TQI method. A case study of a high-speed railway track was performed using the two methods, and the results were verified with the original data. It was found that the TQI method identified only one obvious risk while the proposed method identified one obvious risk and two potential risks. This suggests that the proposed method is more accurate in identifying the risky sections than the TQI method.
\end{abstract}

Keywords: high-speed track; geometric parameters; dynamic comprehensive evaluation; combined weight; incentive factor-based dynamic comprehensive evaluation

\section{Introduction}

With the rapid development of high-speed railway technology, the dynamic performance requirements for high-speed trains are becoming increasingly demanding due to the increase in vehicle speed. This brings a significant challenge to the service quality of high-speed railway tracks. However, wheel-rail nonlinear interaction leads to a constant deterioration in the service quality of high-speed tracks, significantly increasing the potential risks to the operation of high-speed trains. Therefore, the need to improve service quality promotes the development of methods for high-speed railway track management.

Many studies have provided qualitative evaluation of high-speed railway tracks. The power spectrum density (PSD) of track irregularity was used to evaluate the railway tracks both qualitatively and quantitatively [1]. Eric et al. [2] presented a new approach to enhancing the assessment of track geometry quality and rail roughness using train-track interaction simulation and wavelength content analysis. The simulations of dynamic track-vehicle interaction were also presented to assess vertical track geometry quality. It proved an effective tool to analyze the collected track geometry, and helped track engineers monitor track condition and make better track maintenance plans [3]. 
J.M. et al. [4] proposed a new method of track evaluation based on the observation of track's structural defects. The method could recognize the causes of track defects along the line and the correlations between geometric and structural defects in track. Methodologies for inspection and evaluation of slab-track quality conditions were developed, and correlations between geometry irregularities and structural conditions were found. The methods have proven to be efficient and practical tools to evaluate slab-track conditions, prioritize the required repair activities, and then make appropriate preventive maintenance decisions [5]. Several methods for evaluating track geometrical quality were presented and compared to each other in reference [6]. The results showed that the rate of track degradation varied according to the measurement method employed [6]. Tan et al. [7] established the probabilistic transfer matrix model between dynamic and static TQI. The model verified that the probabilistic transfer matrix model could be used for quantitative reference in track fine adjustment and dynamic acceptance tests. $\mathrm{Li}$ [8] summarized the methods and criteria available for track geometric quality assessment. Lv [9] established a risk assessment model for the underpass bridge subgrade based on a fuzzy comprehensive assessment method. Siddhartha et al. [10] developed a data-driven condition-based policy for the inspection and maintenance of track geometry and found that the track with low level of TQI still suffered from the risk of failure due to geometry defects. Track quality evaluation was based not only on track geometry but also on vehicle performance. A CNN-LSTM (the combination of the convolutional neural network and short-term memory) model was proposed to predict vehicle-body vibration, which was helpful in locating potential track geometry defects [11]. Although these evaluation methods can provide better qualitative results, they remain unable to adequately describe the change in service quality of track based on a single physical quantity.

To tackle this issue, pioneering scientists and engineers have proposed comprehensive evaluation strategies that evaluate multiple indicators and multiple units at the same time using a relatively systematic, standardized method, such as DCE and static comprehensive evaluation (SCE). Previous research has presented various methods of SCE, including subjective weighting (e.g., AHP, binary fuzzy comparison method (BFCM)), objective weighting (e.g., the technique for ordering of preference by similarity to ideal solution (TOPSIS), Delphi, entropy weight method [12], coefficient of variation, factor analysis, principal component analysis (PCA)) and combination weighting (e.g., AHP-TOPSIS [13], AHP-grey relational analysis process [14], entropy weight-based lower confidence bounding approach [12]). Saaty [15] first applied the analytic hierarchy process to determine weight indicators. Charnes et al. [16] proposed the data envelopment analysis (DEA) and used it to evaluate intellectual capital [17], railway [18], etc. Xu et al. [19] combined the AHP and the DEA to evaluate the economic benefits of energy-saving technology applications. Besides, there are other methods of comprehensive evaluation, such as the fuzzy comprehensive evaluation method, artificial network neural evaluation, and grey comprehensive evaluation. Du et al. provided an overview of the concepts, advantages, and disadvantages of these methods [20]. Because of subjectivity, the evaluation of the same object based on different evaluation criteria would lead to different results. Moreover, objective weighting is affected by random data error or the lack of data even though the method avoids the influence of subjectivity. To overcome these limitations, combination weighting methods have been proposed, which can be divided into three categories: Combination of the evaluation process, combination of the evaluation results, and combination of the evaluation method itself [21]. If a time series is added to SCE, the evaluation problem becomes DCE. Guo [22] used a time series solid data table to record the comprehensive evaluation results for the evaluated object over a sustained period of time. Xu et al. [23] evaluated the livable city using a combination of the dynamic information entropy and fuzzy comprehensive evaluation. The positive and negative incentive lines were set up according to the evaluation of the objects, and the predicted values were obtained based on a first-order one-variable grey model. The rewarded and punished incentive lines were introduced to evaluate the objects [24]. Ma et al. [25] proposed a method of DCE based on the gain level incentive, which played a role in stimulating and guiding the dynamic development of evaluated objects. Zhang et al. [26] presented a mapping algorithm for weight determination and introduced acceleration and acceleration 
index to reflect the variation in index values over time. This algorithm could better determine the weight information's ranges caused by fluctuations in the index in different stages, and it could coordinate the adjustments of evaluation index values and weight information. The existing literature also provides other methods, including double incentives dynamic comprehensive [27], dynamic evaluation method based on TOWA operator, dynamic evaluation method integrating SOM and K-means clustering algorithm [28], and dynamic comprehensive evaluation method based on the accelerated genetic algorithm [29].

A review of the literature shows that a large number of studies have focused on SCE methods. The TQI $[30,31]$ is the primary method for comprehensive evaluation of high-speed railway lines. This method evaluates the average quality of track segments based on statistical characteristic value, and it is used as the key index to evaluate the state of track geometry [8], This paper describes the TQI method in detail in the third section. TQI is calculated as the ratio of the traced space curve length to the track segment length in the U.S. [10]. In other countries, TGI and J are another two common indexes used to evaluate track geometry [32]. Other computing modes used in a different country have been described by the authors of [6]. The track geometric parameters considered in the present paper were the surface $\left(\mathrm{P}_{p r f}\right)$, track alignment $\left(\mathrm{P}_{\text {aln }}\right)$, track gauge $\left(\mathrm{P}_{\text {gage }}\right)$, cross-level $\left(\mathrm{P}_{x l v l}\right)$, and twist $\left(\mathrm{P}_{\text {warp }}\right)$. Without loss of generality, this paper investigated only five prevailing track geometry measures: (1) Surface: The deviation of rail top surface from its design position in the vertical direction. It is divided into left surface and right surface; (2) Alignment: The deviation of the gauge point inside the rail from its design position in the transverse direction. It is divided into left alignment and right alignment; (3) Cross-level: The difference in height between the top surfaces of the left and right rails in the same rail cross-section; (4) Gauge: The shortest distance between the left and right steel rails within the same rail cross-section; (5) Twist: The horizontal algebraic difference between two points that are $3-\mathrm{m}$ apart in the longitudinal direction. Peak management was used to evaluate these parameters, and the standard deviation management (mean management) was used to evaluates the sum of the parameters' standard deviations. This method can reflect the overall state of the equipment, but it still deals with SCE and is ineffective in identifying potential risks in the results.

The remainder of this paper is arranged as follows. In the second section, the background of literature research is provided, along with the purpose of this paper. In the third section, the research methodology is discussed in detail. The fourth section gives a case analysis and discussion. Conclusions and future work are discussed in the fifth section.

\section{Background}

This paper analyzed the geometric data for the period from July 2011 to December 2018 supplied by an infrastructure management department. The analysis results are shown in Figure 1. The traffic speed was between $200-250 \mathrm{~km} / \mathrm{h}$. In China, the TQI is usually calculated for $200-\mathrm{m}$ sections and track irregularities are measured using track inspection cars. The length of the track studied in this paper was from K997 to K1075, with K997 referring to the location at a distance of $997 \mathrm{~km}$ on the high-speed track and K1075 the location at a distance of $1075 \mathrm{~km}$. The TQI and the track geometry parameters were all below the corresponding management values: $\mathrm{P}_{p r f}$ was $1.4 \mathrm{~mm}, \mathrm{P}_{\text {aln }}$ was $1.0 \mathrm{~mm}$, $\mathrm{P}_{x l v l}$ was $1.1 \mathrm{~mm}, \mathrm{P}_{\text {gage }}$ was $0.9 \mathrm{~mm}$, and $\mathrm{P}_{\text {twist }}$ was $1.2 \mathrm{~mm}$ (Table 1) [33]. Moreover, $\mathrm{P}_{p r f, L}$ and $\mathrm{P}_{p r f, R}$ had a strong influence on TQI, as shown in Figure 1a. Sometimes, $\mathrm{P}_{p r f, L}$ and $\mathrm{P}_{p r f, R}$ determine the trend of TQI. As can be seen in Figure 1b, the variation of vertical standard deviation caused the seasonal variation and increasing trend of track quality index. 


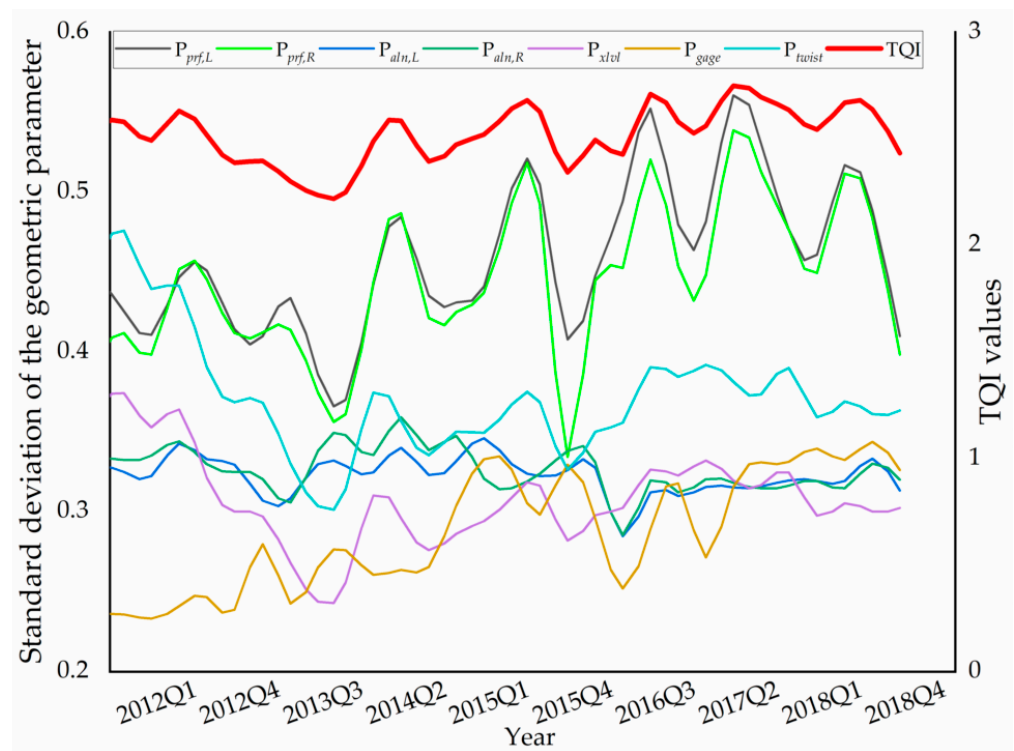

(a)

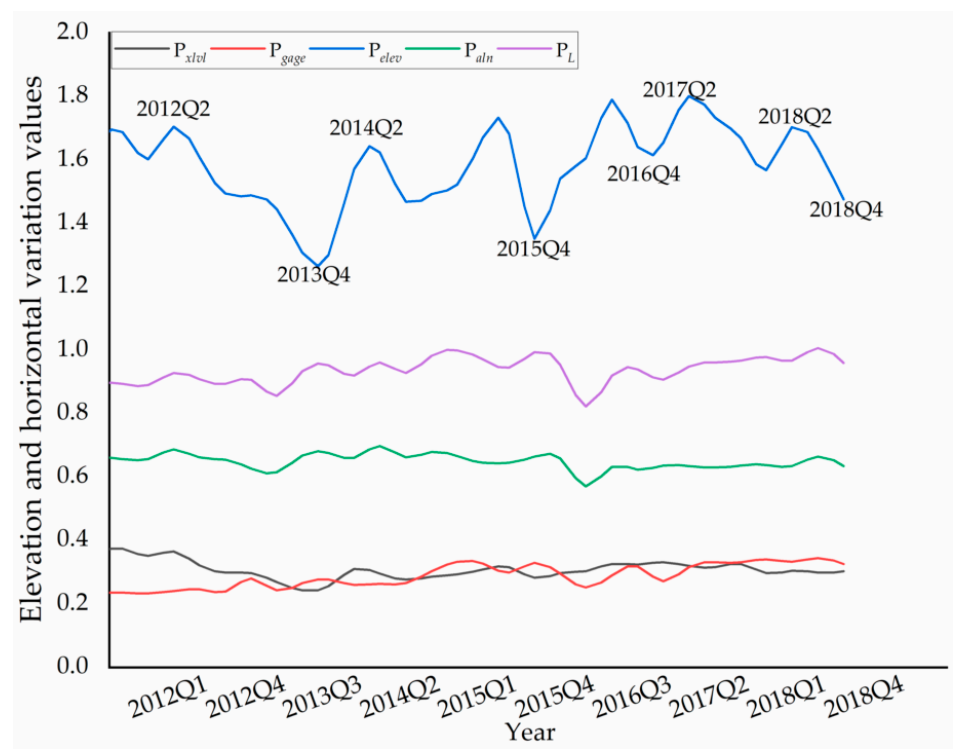

(b)

Figure 1. (a) Track quality index (TQI) and track geometric parameters and (b) elevation and horizontal variation. $\mathrm{P}_{p r f, L}, \mathrm{P}_{p r f, R}, \mathrm{P}_{a l n, L}$, and $\mathrm{P}_{a l n, R}$ are the left surface irregularity, right surface irregularity, left track alignment irregularity, and right track alignment irregularity, respectively; $\mathrm{P}_{\text {elev }}$ is the sum of $\mathrm{P}_{p r f, L}, \mathrm{P}_{p r f, R}, \mathrm{P}_{x l v l}$, and $\mathrm{P}_{\text {twist }} ; \mathrm{P}_{a l n}$ is the sum of $\mathrm{P}_{a l n, L}$, and $\mathrm{P}_{a l n, R} ;$ and $\mathrm{P}_{L}$ is the sum of $\mathrm{P}_{a l n, L}, \mathrm{P}_{a l n, R}$ and $\mathrm{P}_{\text {gage }}$.

Table 1. Management standards for TQI and single parameter's standard deviation for 200-m track segment for different speed classes (unit: $\mathrm{mm}$ ).

\begin{tabular}{ccccccccc}
\hline Speed & $\mathbf{P}_{a l n, L}$ & $\mathbf{P}_{a l n, R}$ & $\mathbf{P}_{p r f, L}$ & $\mathbf{P}_{p r f, R}$ & $\mathbf{P}_{x l v l}$ & $\mathbf{P}_{\text {gage }}$ & $\mathbf{P}_{\text {twist }}$ & TQI \\
\hline $200<V \leq 250$ & 1.0 & 1.0 & 1.4 & 1.4 & 0.9 & 1.1 & 1.2 & 8 \\
\hline
\end{tabular}

The original values of these geometric parameters were collected and analyzed in detail (Table 2). It was found that the values of some parameters exceeded the management values along the segment between K1006 K1023 (K1006 and K1023 represent the locations at distances of 1006 km and 1023 km, 
respectively, on the high-speed track), which cannot be identified in Figure 1. Furthermore, for each section, the TQI values based on the track geometric parameters were equal, and the influence of vertical standard deviation was not remarkable.

Table 2. Value of the TQI and geometric parameters (unit: $\mathrm{mm}$ ).

\begin{tabular}{cccccccccc}
\hline $\mathbf{K M}$ & $\mathbf{P}_{\boldsymbol{a l n}, \mathbf{L}}$ & $\mathbf{P}_{\boldsymbol{a l n}, \boldsymbol{R}}$ & $\mathbf{P}_{\boldsymbol{p r f}, \boldsymbol{L}}$ & $\mathbf{P}_{\boldsymbol{p r f}, \boldsymbol{R}}$ & $\mathbf{P}_{\text {xlv }}$ & $\mathbf{P}_{\text {gage }}$ & $\mathbf{P}_{\text {twist }}$ & TQI & Overrun \\
\hline 1022.8 & 1.59 & 0.78 & 0.81 & 0.86 & 0.5 & 3.26 & 0.53 & 8.32 & $\mathrm{Y}$ \\
1023 & 1.45 & 0.69 & 0.7 & 0.8 & 0.62 & 3.19 & 0.59 & 8.03 & $\mathrm{Y}$ \\
1025 & 1.67 & 0.6 & 0.37 & 0.37 & 0.56 & 3.29 & 0.5 & 7.36 & $\mathrm{Y}$ \\
$\vdots$ & $\vdots$ & $\vdots$ & $\vdots$ & $\vdots$ & $\vdots$ & $\vdots$ & $\vdots$ & $\vdots$ & \\
1006.2 & 0.63 & 0.62 & 0.87 & 0.82 & 0.81 & 0.59 & 0.99 & 5.33 & $\mathrm{~N}$ \\
\hline
\end{tabular}

To overcome the abovementioned limitations, the weights of the geometric parameters should be determined by the combination weighting method based on the correlation coefficient. The combination of AHP and entropy weight method was used in this paper. Moreover, an incentive factor-based DCE and time series were combined for effective management of high-speed railway tracks. The method can be used by rail administrations for safety control and track maintenance, inspection, and rehabilitation.

\section{Evaluation Methods}

\subsection{Traditional TQI Method}

The TQI [34] method is to calculate the standard deviations of the seven geometric parameters for a 200-m track section, including the left surface irregularity $\left(\mathrm{P}_{p r f, L}\right)$, right surface irregularity $\left(\mathrm{P}_{p r f, R}\right)$, left track alignment irregularity $\left(\mathrm{P}_{a l n, L}\right)$, right track alignment irregularity $\left(\mathrm{P}_{a l n, R}\right)$, track gauge irregularity $\left(\mathrm{P}_{\text {gage }}\right)$, cross-level irregularity $\left(\mathrm{P}_{x l v l}\right)$, and twist $\left(\mathrm{P}_{\text {twist }}\right)$. The $T Q I$ value indicates the degree of dispersion of irregularity along the 200-m section [34]. It is calculated using the formula below:

$$
T Q I=\sum_{i=1}^{7} \sigma_{i}
$$

where $\sigma_{i}(i=(1,2,3,4,5,6,7))$ represents the standard deviation of each geometric parameter, which can be expressed as

$$
\sigma_{i}=\sqrt{\frac{1}{n} \sum_{j=1}^{n}\left(x_{i j}^{2}-\bar{x}_{i}^{2}\right)}
$$

where $x_{i j}$ is the monitoring value of each geometric parameter; and $\bar{x}_{i}$ represents the mean value of the $i$ th geometric parameter and can be expressed as

$$
\bar{x}_{i}=\frac{1}{n} \sum_{j=1}^{n} x_{i j}
$$

where $n$ is the number of the monitoring points along the $200-\mathrm{m}$ section. $n$ was set to 800 in this study.

\subsection{Combination Weighting Method}

As discussed in Section 1, the combination weighting method can overcome subjectivity and random data error or the lack of data to some extent. The combined weight can be formulated as

$$
\omega=\alpha \omega_{1}+\beta \omega_{2}
$$

where $\alpha$ and $\beta$ are the subjective and objective weights, respectively. They are unknown parameters, and have the following relationship:

$$
\alpha>0, \beta>0, \alpha^{2}+\beta^{2}=1
$$


The value of the unknown parameters $\alpha, \beta$ can be obtained by the constrained maximization equation as follows:

$$
\begin{aligned}
& \max \omega=\alpha \omega_{1}+\beta \omega_{2} \\
& s, t:\left\{\begin{array}{l}
\alpha>0, \beta>0 \\
\alpha^{2}+\beta^{2}=1
\end{array}\right.
\end{aligned}
$$

Then, Equation (3) can be solved by the maximum likelihood estimation (MLE)-Lagrange conditioned extreme value. Then, $\alpha$ and $\beta$ can be expressed as

$$
\begin{aligned}
& \alpha=\frac{\omega_{1}^{2}}{\sqrt{\omega_{1}^{2}+\omega_{2}^{2}}} \\
& \beta=\frac{\omega_{2}^{2}}{\sqrt{\omega_{1}^{2}+\omega_{2}^{2}}}
\end{aligned}
$$

where $\alpha^{\prime}$ and $\beta^{\prime}$ are obtained by the normalization and standardization of $\alpha$ and $\beta$, respectively. The weight of indexes $\omega^{\prime}$ can be expressed as

$$
\omega^{\prime}=\alpha^{\prime} \omega_{1}+\beta^{\prime} \omega_{2}
$$

\begin{tabular}{|c|c|c|c|}
\hline Time & $t_{1}$ & $\ldots$ & $t_{T}$ \\
\hline- & $\begin{array}{llll}x_{1} & x_{2} & \cdots & x_{m} \\
\end{array}$ & $\cdots$ & $\begin{array}{llll}x_{1} & x_{2} & \cdots & x_{m} \\
\end{array}$ \\
\hline $\begin{array}{l}C_{1} \\
C_{2}\end{array}$ & $\begin{array}{l}x_{11}^{\prime}\left(t_{1}\right) x_{12}^{\prime}\left(t_{1}\right) \cdots x_{1 m}^{\prime}\left(t_{1}\right) \\
x_{21}^{\prime}\left(t_{1}\right) x_{22}^{\prime}\left(t_{1}\right) \cdots x_{2 m}^{\prime}\left(t_{1}\right)\end{array}$ & $\begin{array}{l}\cdots \\
\cdots\end{array}$ & $\begin{array}{l}x_{11}^{\prime}\left(t_{T}\right) x_{12}^{\prime}\left(t_{T}\right) \cdots x_{1 m}^{\prime}\left(t_{T}\right) \\
x_{21}^{\prime}\left(t_{T}\right) x_{22}^{\prime}\left(t_{T}\right) \cdots x_{2 m}^{\prime}\left(t_{T}\right)\end{array}$ \\
\hline$\vdots$ & : & $\cdots$ & \\
\hline$C_{n}$ & $x_{n 1}^{\prime}\left(t_{1}\right) x_{n 2}^{\prime}\left(t_{1}\right) \cdots x_{n m}^{\prime}\left(t_{1}\right)$ & $\cdots$ & $x_{n 1}^{\prime}\left(t_{T}\right) x_{n 2}^{\prime}\left(t_{T}\right) \cdots x_{n m}^{\prime}\left(t_{T}\right)$ \\
\hline
\end{tabular}

\subsection{An Incentive Factor-Based DCE Method}

Suppose there are $n$ evaluated objects and $m$ evaluation indexes. The multidimensional time series can be expressed in the forms shown in Table 3.

Table 3. Multidimensional time series.

In this table, $x_{i j}^{\prime}\left(t_{k}\right)$ represents the standard deviation of each geometric parameter of the $i$ th evaluation object $i(i=1,2,3, \cdots, n)$ at time $t_{k}(k=1,2,3, \cdots, T)$; and $C_{i}$ represents the $i$ th evaluation object.

The parameters above should be nondimensionalized through normalization and standardization. In other words, they should be converted to maximized standard data by a method which involves the following two steps.

Step 1: Nondimensionalization process:

There are many methods to realize nondimensionalization, such as z-score, min-max, and normalization. The min-max method was applied to remove the unit limit on each parameter and convert it to a dimensionless quantity in this paper.

Firstly, the standard deviation of each geometric parameter can be expressed as

$$
Z_{i j}\left(t_{k}\right)=\left[\begin{array}{ccccccc}
x_{11}^{\prime}\left(t_{1}\right) & \cdots & x_{1 m}^{\prime}\left(t_{1}\right) & \cdots & x_{11}^{\prime}\left(t_{T}\right) & \cdots & x_{1 m}^{\prime}\left(t_{T}\right) \\
\cdots & \ddots & \cdots & \cdots & \cdots & \ddots & \cdots \\
x_{11}^{\prime}\left(t_{1}\right) & \cdots & x_{n m}^{\prime}\left(t_{1}\right) & \cdots & x_{n 1}^{\prime}\left(t_{T}\right) & \cdots & x_{n m}^{\prime}\left(t_{T}\right)
\end{array}\right] .
$$


Then, the values are set between 0 and 1 by the linear transformation of the original data. Furthermore, the function can be expressed as

$$
Z_{i j}^{\prime}\left(t_{k}\right)=\frac{x_{i j}^{\prime}\left(t_{k}\right)-\min \left(x_{1 j}^{\prime}\left(t_{k}\right) x_{2 j}^{\prime}\left(t_{k}\right) \cdots x_{n j}^{\prime}\left(t_{k}\right)\right)}{\max \left(x_{1 j}^{\prime}\left(t_{k}\right) x_{2 j}^{\prime}\left(t_{k}\right) \cdots x_{n j}^{\prime}\left(t_{k}\right)\right)-\min \left(x_{1 j}^{\prime}\left(t_{k}\right) x_{2 j}^{\prime}\left(t_{k}\right) \cdots x_{n j}^{\prime}\left(t_{k}\right)\right)} .
$$

Step 2: Maximization process:

The key is to identify whether the type of data is minimal, intermediate, or interval. The data in this paper were classified as intermediate. Therefore, we utilized the forward function to describe it as

$$
\max -\widetilde{x}_{i j}^{\prime}\left(t_{k}\right)
$$

The matrix obtained after the data preprocessing had the following form:

$$
\widetilde{Z}_{i j}\left(t_{k}\right)=\left[\begin{array}{ccccccc}
\widetilde{x}_{11}^{\prime}\left(t_{1}\right) & \ldots & \widetilde{x}_{1 m}^{\prime}\left(t_{1}\right) & \ldots & \widetilde{x}_{11}^{\prime}\left(t_{T}\right) & \ldots & \widetilde{x}_{1 m}^{\prime}\left(t_{T}\right) \\
\ldots & \ddots & \ldots & \ldots & \ldots & \ddots & \ldots \\
\widetilde{x}_{11}^{\prime}\left(t_{1}\right) & \ldots & \widetilde{x}_{n m}^{\prime}\left(t_{1}\right) & \ldots & \widetilde{x}_{n 1}^{\prime}\left(t_{T}\right) & \ldots & \widetilde{x}_{n m}^{\prime}\left(t_{T}\right)
\end{array}\right]
$$

SCE matrix $Y$ was obtained by the combination of the AHP and entropy method in this paper.

$$
Y=\left[\begin{array}{cccc}
y_{1}\left(t_{1}\right) & y_{1}\left(t_{2}\right) & \cdots & y_{1}\left(t_{T}\right) \\
y_{2}\left(t_{1}\right) & y_{2}\left(t_{2}\right) & \cdots & y_{2}\left(t_{T}\right) \\
\vdots & \vdots & & \ddots \\
y_{n}\left(t_{1}\right) & y_{n}\left(t_{2}\right) & \cdots & y_{n}\left(t_{T}\right)
\end{array}\right]
$$

where $y_{i}\left(t_{k}\right)$ is the static evaluation value for the $i$ th evaluated object at time $t_{k}$. The evaluation value for the evaluated object is then enlarged by an incentive model, where the optimal incentive $v_{i}^{+}\left(t_{k}\right)$ and the negative incentive $v_{i}^{-}\left(t_{k}\right)$ can be expressed as

$$
\begin{aligned}
& v_{i}^{+}=\left\{\begin{array}{ll}
y_{i}^{+}\left(t_{k}\right)-y_{i}\left(t_{k}\right) & y_{t}^{+}\left(t_{k}\right)>y_{i}\left(t_{k}\right) \\
0 & \text { others }
\end{array},\right. \\
& v_{i}^{-}=\left\{\begin{array}{ll}
y_{i}\left(t_{k}\right)-y_{i}^{-}\left(t_{k}\right) & y_{i}\left(t_{k}\right)>y_{t}^{-}\left(t_{k}\right) \\
0 & \text { others }
\end{array},\right.
\end{aligned}
$$

where $y_{i}^{+}\left(t_{k}\right)$ and $y_{i}^{-}\left(t_{k}\right)$ are the optimal incentive point and the negative incentive point, respectively, for the $i$ th evaluated object at time $t_{k}$. Here, the data are weighted again based on incentive so that the risk, obvious or potential, can be highlighted. Suppose there is no motivation at the initial moment $t_{1}$. Then $v_{i}^{+}\left(t_{k}\right)$ and $v_{i}^{-}\left(t_{k}\right)$ are both zero. From the values of $v_{i}^{+}\left(t_{k}\right)$ and $v_{i}^{-}\left(t_{k}\right)$, average maximum gain $\eta^{\max }$, average minimum gain $\eta^{\text {min }}$, average gain $\bar{\eta}$, optimal gain level $\eta^{+}$, and inferior gain level $\eta^{-}$can be obtained by the following formulas:

$$
\begin{gathered}
\eta^{\max }=\max _{i}\left(\frac{1}{T-1} \sum_{k=1}^{T-1}\left(y_{i}\left(t_{k+1}\right)-y_{i}\left(t_{k}\right)\right)\right) \\
\eta^{\min }=\min _{i}\left(\frac{1}{T-1} \sum_{k=1}^{T-1}\left(y_{i}\left(t_{k+1}\right)-y_{i}\left(t_{k}\right)\right)\right), \\
\bar{\eta}=\frac{1}{n(T-1)} \sum_{i=1}^{n} \sum_{k=1}^{T-1}\left(y_{i}\left(t_{k+1}\right)-y_{i}\left(t_{k}\right)\right) \\
\eta^{+}=\bar{\eta}+k^{+}\left(\eta^{\max }-\bar{\eta}\right) \\
\eta^{-}=\bar{\eta}-k^{-}\left(\bar{\eta}-\eta^{\min }\right)
\end{gathered}
$$


where $k^{+}$and $k^{-}$represent the floating coefficients of the evaluated object. Their values can be set based on specialist experience at between 0 and 1 . Generally, specialists in this field have certain expectations about the overall development status of a given evaluated object. For example, when the evaluated object is in its best, normal, or worst status, this psychological expectation can be realized by setting the floating coefficients $k^{+}$and $k^{-}$. Then, $y_{i}^{+}\left(t_{k}\right)$ and $y_{i}^{-}\left(t_{k}\right)$ can be obtained as follow

$$
\begin{aligned}
\eta^{+} & =y_{i}^{+}\left(t_{k}\right)-y_{i}\left(t_{k-1}\right) \\
\eta^{-} & =y_{i}^{-}\left(t_{k}\right)-y_{i}\left(t_{k-1}\right)
\end{aligned}
$$

where $k=(1,2,3, \cdots T)$.

By substituting $y_{i}^{+}\left(t_{k}\right), y_{i}^{-}\left(t_{k}\right)$ and SCE matrix $Y$ into Equations (14) and (15), $v_{i}^{+}\left(t_{k}\right)$ and $v_{i}^{-}\left(t_{k}\right)$ are obtained. Then the DCE value can be expressed as

$$
Z_{i}\left(t_{k}\right)=h^{+} v_{i}^{+}\left(t_{k}\right)+y_{i}\left(t_{k}\right)-h^{-} v_{i}^{-}\left(t_{k}\right),
$$

where $h^{+}$and $h^{-}\left(h^{+}, h^{-}>0\right)$ are the optimal incentive factor and the negative incentive factor, respectively; and $\left.h^{+} v_{i}^{+}\left(t_{k}\right)\right)$ and $\left.h^{-} v_{i}^{-}\left(t_{k}\right)\right)$ are the optimal incentive value and the negative incentive value, respectively.

The incentive factors $h^{+}$and $h^{-}$are determined by the following two rules:

Rule 1: Incentive total proportionality rule: The total proportionality of the optimal incentive and negative incentive is the direct proportion for all the evaluation objects, which can be expressed as

$$
r=\frac{h^{+} \sum_{i=1}^{n} \sum_{k=1}^{T} v_{i}^{+}\left(t_{k}\right)}{h^{-} \sum_{i=1}^{n} \sum_{k=1}^{T} v_{i}^{-}\left(t_{k}\right)},
$$

where $r\left(r \in R^{+}\right)$is the proportionality value, which reflects the intention of the evaluator to highlight a decision. When $r>1$, it means the total proportion of optimal incentive is higher than that of negative incentive. When $r<1$, it means the total proportion of optimal incentive is less than that of negative incentive. When $r=1$, it means the total proportion of optimal incentive is equal to that of negative incentive.

Rule 2: Balanced incentive rule: The sum of optimal incentive and negative incentive factors is 1 , i.e.,

$$
h^{+}+h^{-}=1
$$

Based on Equations (20) and (21), $h^{+}, h^{-}$are obtained. The total DCE value for the $i$ th evaluated object at time $T$ after a given incentive can be obtained as follow:

$$
Z_{i}=\sum_{k=1}^{n} \lambda_{k} Z_{i}\left(t_{k}\right)
$$

where $\lambda_{k}$ represents time factors. Suppose $\lambda_{k}=e^{k / 2 n}$ in this paper, which means the parameter values increase as time goes on. Besides, $\lambda_{k}$ is 1 if the influence of time is disregarded.

\section{Case Study}

A set of geometric data supplied by an infrastructure management department was used here. The data were collected every half month from January 2020 to March 2020, so T was 6. The speed was between 200 250 km/h and the test section was from K997 to K1075. A total of 395 objects were evaluated.

\subsection{Data Processing}

1. The basic data were standardized and normalized according to Equations (10) and (11). Due to the large amount of data, only part of the results was presented in the paper (see Table 4). 
Table 4. Results of data standardization and normalization (unit: $\mathrm{mm}$ ).

\begin{tabular}{|c|c|c|c|c|c|c|c|c|c|c|c|c|c|c|}
\hline \multicolumn{7}{|c|}{$t_{1}$} & \multicolumn{2}{|l|}{$t_{k}$} & \multicolumn{5}{|c|}{$t_{1}$} & \multirow[b]{2}{*}{$\mathbf{P}_{\text {twist }}$} \\
\hline $\mathbf{P}_{p r f, L}$ & $\mathbf{P}_{p r f, R}$ & $\mathbf{P}_{a l n, L}$ & $\mathbf{P}_{a l n, R}$ & $\mathbf{P}_{\text {gage }}$ & $\mathbf{P}_{x l v l}$ & $\mathbf{P}_{\text {twist }}$ & $\ldots$ & $\mathbf{P}_{p r f, L}$ & $\mathbf{P}_{p r f, R}$ & $\mathbf{P}_{a l n, L}$ & $\mathbf{P}_{a l n, R}$ & $\mathbf{P}_{\text {gage }}$ & $\mathbf{P}_{x l v l}$ & \\
\hline 0.9951 & 0.9948 & 0.9967 & 0.9965 & 0.9976 & 0.9787 & 0.9586 & $\cdots$ & 0.9935 & 0.9956 & 0.9965 & 0.9970 & 0.9976 & 0.9787 & 0.9301 \\
\hline 0.9937 & 0.9951 & 0.9975 & 0.9968 & 0.9992 & 0.9916 & 0.9845 & $\ldots$ & 0.9941 & 0.9974 & 0.9978 & 0.9975 & 0.9988 & 0.9951 & 0.9900 \\
\hline$\ldots$ & $\cdots$ & $\ldots$ & $\ldots$ & $\ldots$ & $\ldots$ & $\ldots$ & $\ldots$ & $\ldots$ & $\ldots$ & $\ldots$ & $\ldots$ & $\ldots$ & $\ldots$ & $\ldots$ \\
\hline 0.9986 & 0.9980 & 0.9965 & 0.9969 & 0.9981 & 0.9903 & 0.9918 & & 0.9912 & 0.9961 & 0.9969 & 0.9971 & 0.9980 & 0.9906 & 0.9905 \\
\hline 0.9929 & 0.9869 & 0.9964 & 0.9954 & 0.9981 & 0.9941 & 0.9873 & & 0.9909 & 0.9924 & 0.9967 & 0.9967 & 0.9980 & 0.9951 & 0.9872 \\
\hline 0.9998 & 0.9964 & 0.9959 & 0.9950 & 0.9984 & 0.9984 & 0.9959 & $\ldots$ & 0.9922 & 0.9937 & 0.9970 & 0.9958 & 0.9968 & 0.9971 & 0.9942 \\
\hline$\ldots$ & $\ldots$ & $\ldots$ & $\ldots$ & $\ldots$ & $\ldots$ & $\ldots$ & $\ldots$ & $\ldots$ & $\ldots$ & $\ldots$ & $\ldots$ & $\ldots$ & $\ldots$ & $\ldots$ \\
\hline
\end{tabular}

2. The Spearman's correlation coefficients between the geometric parameters were calculated and the results are presented in Table 5. This step is the basis for determining the parameters' weights. Especially when subjective weighting is applied, the experts can give an appropriate relative importance to the parameters in terms of the correlation coefficient.

Table 5. The correlation coefficient between geometric parameters (unit: $\mathrm{mm}$ ).

\begin{tabular}{ccccccccc}
\hline Correlation Coefficient & $\mathbf{P}_{\boldsymbol{p r f}, \boldsymbol{L}}$ & $\mathbf{P}_{\boldsymbol{p r f}, \boldsymbol{R}}$ & $\mathbf{P}_{\text {aln }, \mathrm{L}}$ & $\mathbf{P}_{\text {aln }, \boldsymbol{R}}$ & $\mathbf{P}_{\text {gage }}$ & $\mathbf{P}_{\text {xlvl }}$ & $\mathbf{P}_{\text {twist }}$ & $\mathbf{T Q I}$ \\
\hline $\mathrm{P}_{\text {prf }, L}$ & 1.000 & $0.934^{* * *}$ & 0.195 & 0.185 & 0.183 & $0.619^{*}$ & 0.531 & $0.841^{* *}$ \\
$\mathrm{P}_{\text {prf }, R}$ & $0.934^{* * *}$ & 1.000 & 0.189 & 0.181 & 0.236 & $0.6483^{*}$ & 0.561 & $0.86^{* *}$ \\
$\mathrm{P}_{\text {aln }, L}$ & 0.195 & 0.189 & 1.000 & $0.775^{*}$ & 0.353 & 0.223 & 0.225 \\
$\mathrm{P}_{\text {aln }, R}$ & 0.185 & 0.181 & $0.775^{*}$ & 1.000 & 0.378 & 0.191 & 0.194 & 0.420 \\
$\mathrm{P}_{\text {gage }}$ & 0.183 & 0.236 & 0.353 & 0.378 & 1.000 & 0.247 & 0.194 & 0.464 \\
$\mathrm{P}_{\text {xlvl }}$ & $0.619^{*}$ & $0.6483^{*}$ & 0.223 & 0.191 & 0.247 & 1.000 & $0.924^{* * *}$ & $0.797^{* *}$ \\
$\mathrm{P}_{\text {twist }}$ & 0.531 & 0.561 & 0.225 & 0.194 & 0.194 & $0.924^{* * *}$ & 1.000 & $0.729^{* *}$ \\
$T Q I$ & $0.841^{* *}$ & $0.86^{* *}$ & 0.420 & 0.425 & 0.464 & $0.797^{* *}$ & $0.729^{* *}$ & 1.000 \\
\hline
\end{tabular}

Note: '*' represents the strength of the correlation between different indicators. ${ }^{* * * \prime}$ means the strongest; ${ }^{* * \prime}$ means stronger; ${ }^{\prime * \prime}$ strong.

3. The weights of the geometric parameters were determined using a combination of AHP and entropy weight method. AHP is a subjective weight determination method, and the weight of each parameter in this paper was determined based on the experts' opinions [35]. Experts usually assign importance to a parameter on a scale of 1 to 9 . The entropy weight method is an objective weight determination method and a detailed mathematical calculation process can be found in $[36,37]$. The final step was to calculate index weight using Equations (3) through (8), and the results are shown in Table 6.

Table 6. Weight of each geometric parameter (unit: $\mathrm{mm}$ ).

\begin{tabular}{cccc}
\hline Indicators & AHP & Entropy & Combination \\
\hline $\mathrm{P}_{\text {prf }, L}$ & 0.277 & 0.1101 & 0.1994 \\
$\mathrm{P}_{\text {prf }, R}$ & 0.277 & 0.1165 & 0.2023 \\
$\mathrm{P}_{\text {aln }, L}$ & 0.057 & 0.1487 & 0.0994 \\
$\mathrm{P}_{\text {aln }, R}$ & 0.057 & 0.1937 & 0.1202 \\
$\mathrm{P}_{\text {gage }}$ & 0.057 & 0.1884 & 0.1178 \\
$\mathrm{P}_{\text {xlvl }}$ & 0.151 & 0.1105 & 0.1324 \\
$\mathrm{P}_{\text {twist }}$ & 0.125 & 0.1321 & 0.1285 \\
\hline
\end{tabular}

Note: $\alpha^{\prime}=0.5363, \beta^{\prime}=0.463$, which were determined using Equations (1)-(5).

The correlation coefficient presented in Table 5 suggests that left surface irregularity and right surface irregularity had the most significant influence on the values of TQI parameters, with the correlation coefficient being 0.841 and 0.86, respectively. Cross-level irregularity and twist irregularity had the second strongest influence, with the correlation coefficient being 0.797 and 0.729 , respectively. The number of the symbol ${ }^{* \prime}$ represents the strength of the correlation between 
different indicators. According to Table 6, these parameters were ranked in order of weight as follows: $\mathrm{P}_{p r f, R}>\mathrm{P}_{p r f, L}>\mathrm{P}_{x l v l}>\mathrm{P}_{\text {twist }}>\mathrm{P}_{\text {aln }, R}>\mathrm{P}_{\text {gage }}>\mathrm{P}_{\text {aln }, L}$. The rankings suggest that surface irregularity had the strongest influence on TQI. Furthermore, the cross-level irregularity and twist irregularity had the second strongest influence. The results are also consistent with Figure 1, which shows that $\mathrm{P}_{p r f, L}$ and $\mathrm{P}_{p r f, R}$ had a strong influence on TQI. The results above can lead to a conclusion that the weights given to the seven parameters are reasonable.

\subsection{An Incentive Factor-Based DCE}

Based on the method described in Section 2 and the processed data obtained in Section 4.1, the SCE matrix can be calculated, and the results are shown in Table 7. The values of the incentive factor-based DCE parameters are shown in Table 8. Moreover, Table 9 shows the values of the optimal incentive point and the negative incentive point.

Table 7. Static comprehensive evaluation (SCE) matrix (unit: $\mathrm{mm}$ ).

\begin{tabular}{ccccccc}
\hline Time & $\boldsymbol{y}_{\boldsymbol{i}}\left(\boldsymbol{t}_{1}\right)$ & $\boldsymbol{y}_{\boldsymbol{i}}\left(\boldsymbol{t}_{2}\right)$ & $\boldsymbol{y}_{\boldsymbol{i}}\left(\boldsymbol{t}_{3}\right)$ & $\boldsymbol{y}_{\boldsymbol{i}}\left(\boldsymbol{t}_{4}\right)$ & $\boldsymbol{y}_{\boldsymbol{i}}\left(\boldsymbol{t}_{5}\right)$ & $\boldsymbol{y}_{\boldsymbol{i}}\left(\boldsymbol{t}_{6}\right)$ \\
\hline$C_{1}$ & 0.98877 & 0.93517 & 0.99274 & 0.941 & 0.98782 & 0.98499 \\
$C_{2}$ & 0.99389 & 0.96277 & 0.99492 & 0.95289 & 0.99579 & 0.99565 \\
$C_{3}$ & 0.98738 & 0.92913 & 0.98881 & 0.91674 & 0.98675 & 0.98954 \\
$C_{i}$ & $\ldots$ & $\ldots$ & $\ldots$ & $\ldots$ & $\ldots$ & $\ldots$ \\
$C_{394}$ & 0.99233 & 0.94992 & 0.99302 & 0.92156 & 0.99355 & 0.99337 \\
$C_{395}$ & 0.99724 & 0.98378 & 0.99784 & 0.95515 & 0.99692 & 0.99482 \\
\hline
\end{tabular}

Table 8. The values of the incentive factor-based dynamic comprehensive evaluation (DCE) parameters.

\begin{tabular}{ccccccc}
\hline Parameters & $\eta^{\max }$ & $\eta^{\min }$ & $\bar{\eta}$ & $\eta^{+}$ & $\boldsymbol{k}^{+}, \boldsymbol{k}^{-}$ & $\mathbf{r}$ \\
\hline Value & 0.0294 & -0.0259 & -0.0012 & 0.00795 & 0.3 & 1 \\
\hline
\end{tabular}

Table 9. Value of the optimal and negative incentive points (unit: $\mathrm{mm}$ ).

\begin{tabular}{cccccccccc}
\hline \multicolumn{2}{c}{$\boldsymbol{t}_{2}$} & \multicolumn{2}{c}{$\boldsymbol{t}_{3}$} & \multicolumn{2}{c}{$\boldsymbol{t}_{4}$} & \multicolumn{2}{c}{$\boldsymbol{t}_{5}$} & \multicolumn{3}{c}{$t_{6}$} \\
\hline OIP & BIP & OIP & BIP & OIP & BIP & OIP & BIP & OIP & BIP \\
$y_{i}^{+}\left(t_{2}\right)$ & $y_{i}^{-}\left(t_{2}\right)$ & $y_{i}^{+}\left(t_{3}\right)$ & $y_{i}^{-}\left(t_{3}\right)$ & $y_{i}^{+}\left(t_{4}\right)$ & $y_{i}^{-}\left(t_{4}\right)$ & $y_{i}^{+}\left(t_{5}\right)$ & $y_{i}^{-}\left(t_{5}\right)$ & $y_{i}^{+}\left(t_{6}\right)$ & $y_{i}^{-}\left(t_{6}\right)$ \\
\hline 0.99672 & 0.98015 & 0.94312 & 0.92655 & 1.00069 & 0.98412 & 0.94895 & 0.93238 & 0.99577 & 0.9792 \\
1.00185 & 0.98526 & 0.97072 & 0.95415 & 1.00288 & 0.98630 & 0.96084 & 0.94427 & 1.00374 & 0.98717 \\
0.99533 & 0.97876 & 0.93708 & 0.92051 & 0.99676 & 0.98019 & 0.92469 & 0.90812 & 0.99470 & 0.97813 \\
$\vdots$ & $\vdots$ & $\vdots$ & $\vdots$ & $\vdots$ & $\vdots$ & $\vdots$ & $\vdots$ & $\vdots$ & $\vdots$ \\
1.00178 & 0.98521 & 0.96024 & 0.94367 & 1.00133 & 0.98476 & 0.92489 & 0.90832 & 0.99912 & 0.98255 \\
0.99106 & 0.97449 & 0.85593 & 0.83936 & 0.97400 & 0.95743 & 0.77636 & 0.75979 & 0.98538 & 0.96881 \\
\hline
\end{tabular}

Note: OIP and BIP are the abbreviations for optimal incentive points and negative incentive points.

Table 10 shows the optimal incentive and the negative incentive control module values. The values $h^{+}$and $h^{-}$calculated by Equations (20) and (21) were 0.5063 and 0.4937 , respectively. Then we can get the DCE value (Table 11) and the total DCE value based on the time factor $\left(\lambda_{k}=e^{k / 2 n}\right)$ (Table 12). The value of TQI for each track section obtained by the traditional method is shown in Table 13. 
Table 10. Optimal and negative incentive control module value.

\begin{tabular}{cccccccccccc}
\hline \multicolumn{1}{c}{$t_{1}$} & \multicolumn{2}{c}{$t_{2}$} & \multicolumn{2}{c}{$t_{3}$} & \multicolumn{2}{c}{$t_{4}$} & \multicolumn{2}{c}{$t_{5}$} & \multicolumn{2}{c}{$t_{6}$} \\
\hline OIV & BIV & OIV & BIV & OIV & BIV & OIV & BIV & OIV & BIV & OIV & BIV \\
$v_{i}^{+}\left(t_{1}\right)$ & $v_{i}^{-}\left(t_{1}\right)$ & $v_{i}^{+}\left(t_{2}\right)$ & $v_{i}^{-}\left(t_{2}\right)$ & $v_{i}^{+}\left(t_{3}\right)$ & $v_{i}^{-}\left(t_{3}\right)$ & $v_{i}^{+}\left(t_{4}\right)$ & $v_{i}^{-}\left(t_{4}\right)$ & $v_{i}^{+}\left(t_{5}\right)$ & $v_{i}^{-}\left(t_{5}\right)$ & $v_{i}^{+}\left(t_{6}\right)$ & $v_{i}^{-}\left(t_{6}\right)$ \\
\hline 0.00000 & 0.00000 & 0.06156 & 0.00000 & 0.00000 & 0.06620 & 0.05969 & 0.00000 & 0.00000 & 0.05544 & 0.01079 & 0.00579 \\
0.00000 & 0.00000 & 0.03906 & 0.00000 & 0.00000 & 0.04077 & 0.04999 & 0.00000 & 0.00000 & 0.05153 & 0.00810 & 0.00848 \\
0.00000 & 0.00000 & 0.06620 & 0.00000 & 0.00000 & 0.06830 & 0.08002 & 0.00000 & 0.00000 & 0.07863 & 0.00516 & 0.01141 \\
$\vdots$ & $\vdots$ & $\vdots$ & $\vdots$ & $\vdots$ & $\vdots$ & $\vdots$ & $\vdots$ & $\vdots$ & $\vdots$ & $\vdots$ & $\vdots$ \\
0.00000 & 0.00000 & 0.04949 & 0.00000 & 0.00000 & 0.04971 & 0.08439 & 0.00000 & 0.00000 & 0.08284 & 0.01272 & 0.00386 \\
0.00000 & 0.00000 & 0.14308 & 0.00000 & 0.00000 & 0.12669 & 0.20559 & 0.00000 & 0.00000 & 0.21764 & 0.00997 & 0.00661 \\
\hline
\end{tabular}

Note: OIV and BIV are the abbreviations for optimal incentive value and negative incentive value, respectively.

Table 11. The DEC value (unit: $\mathrm{mm}$ ).

\begin{tabular}{cccccc}
\hline $\boldsymbol{Z}_{\boldsymbol{i}}\left(\boldsymbol{t}_{1}\right)$ & $\boldsymbol{Z}_{\boldsymbol{i}}\left(\boldsymbol{t}_{2}\right)$ & $\boldsymbol{Z}_{\boldsymbol{i}}\left(\boldsymbol{t}_{3}\right)$ & $\boldsymbol{Z}_{\boldsymbol{i}}\left(\boldsymbol{t}_{4}\right)$ & $\boldsymbol{Z}_{\boldsymbol{i}}\left(\boldsymbol{t}_{5}\right)$ & $\boldsymbol{Z}_{\boldsymbol{i}}\left(\boldsymbol{t}_{6}\right)$ \\
\hline 0.98877 & 0.96633 & 0.96006 & 0.97123 & 0.96045 & 0.98759 \\
0.99389 & 0.98255 & 0.97480 & 0.97820 & 0.97036 & 0.99556 \\
0.98738 & 0.96265 & 0.95509 & 0.95726 & 0.94793 & 0.98652 \\
$\vdots$ & $\vdots$ & $\vdots$ & $\vdots$ & $\vdots$ & $\vdots$ \\
0.99383 & 0.97735 & 0.96884 & 0.95967 & 0.95027 & 0.99094 \\
0.98311 & 0.92043 & 0.90350 & 0.87250 & 0.86999 & 0.97720 \\
\hline
\end{tabular}

Table 12. The DCE value based on time factors $\lambda_{k}$.

\begin{tabular}{cccccccc}
\hline Time & $\boldsymbol{t}_{1}$ & $\boldsymbol{t}_{2}$ & $\boldsymbol{t}_{3}$ & $\boldsymbol{t}_{4}$ & $\boldsymbol{t}_{5}$ & $\boldsymbol{t}_{6}$ & Value \\
\hline$\lambda_{k}=e^{k / 2 n}$ & 1.0014 & 1.0028 & 1.0042 & 1.0056 & 1.007 & 1.0084 & - \\
$C_{1}$ & 0.99016 & 0.96904 & 0.96410 & 0.97667 & 0.96718 & 0.99589 & 5.86302 \\
$C_{2}$ & 0.99528 & 0.98530 & 0.97889 & 0.98368 & 0.97715 & 1.00393 & 5.92422 \\
$C_{3}$ & 0.98876 & 0.96534 & 0.95910 & 0.96262 & 0.95457 & 0.99481 & 5.82520 \\
$C_{i}$ & $\vdots$ & $\vdots$ & $\vdots$ & $\vdots$ & $\vdots$ & $\vdots$ & $\vdots$ \\
$C_{394}$ & 0.99522 & 0.98009 & 0.97291 & 0.96505 & 0.95692 & 0.99926 & 5.86945 \\
$C_{395}$ & 0.98449 & 0.92300 & 0.90730 & 0.87739 & 0.87608 & 0.98541 & 5.55367 \\
\hline
\end{tabular}

Table 13. TQI of each high-speed track section evaluated (unit: $\mathrm{mm}$ ).

\begin{tabular}{ccccccc}
\hline $\boldsymbol{C}$ & $\boldsymbol{C}_{1}$ & $\boldsymbol{C}_{2}$ & $\boldsymbol{C}_{3}$ & $\boldsymbol{C}_{\boldsymbol{i}}$ & $\boldsymbol{C}_{394}$ & $\boldsymbol{C}_{395}$ \\
\hline TQI & 0.99381 & 0.99834 & 0.99287 & $\ldots$ & 0.99585 & 0.98349 \\
\hline
\end{tabular}

For a comparison of the two methods, the values shown in Tables 12 and 13 are plotted in Figure 2. The curve representing the time factor-based DCE showed fluctuations on $C_{254} \sim C_{269}, C_{338} \sim C_{369}$, and $C_{30} \sim C_{52}$, which suggests that there may be three risky sections. The corresponding sections were K1023 K1024, K1004 K1005, K1067 K1068, which are partly shown in this paper. However, the curve representing TQI just revealed one risky section, which was $C_{254} \sim C_{269}$, and the TQI values of other parts were so stable that we could not identify any risk at all. To verify the result, each geometric parameter was analyzed, and the corresponding trend lines for the risky sections are given in Figures 3-5. The limit values for the geometric parameters are shown in Table 14. 


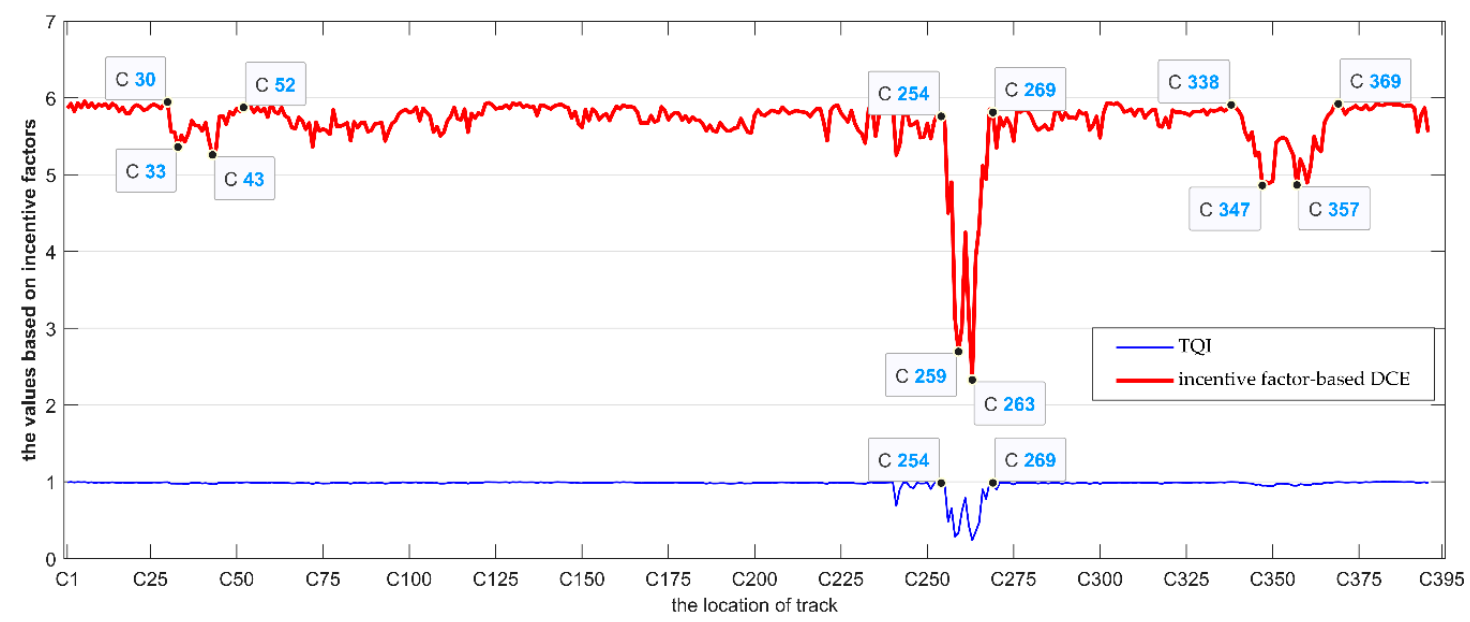

Figure 2. Comparison of the TQI and the incentive factor-based DCE.
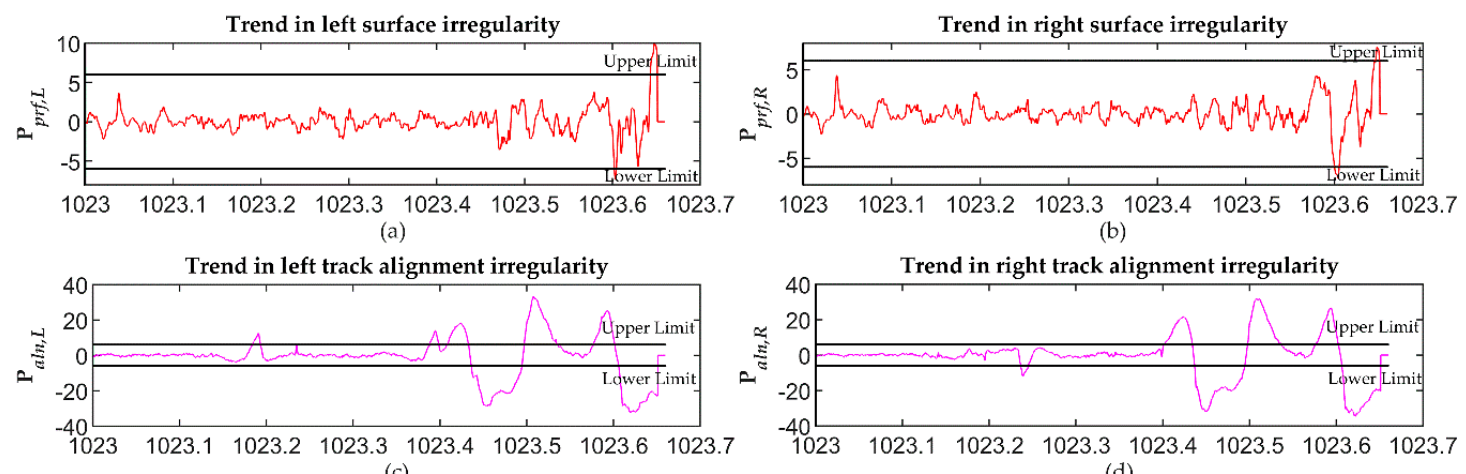

(c)
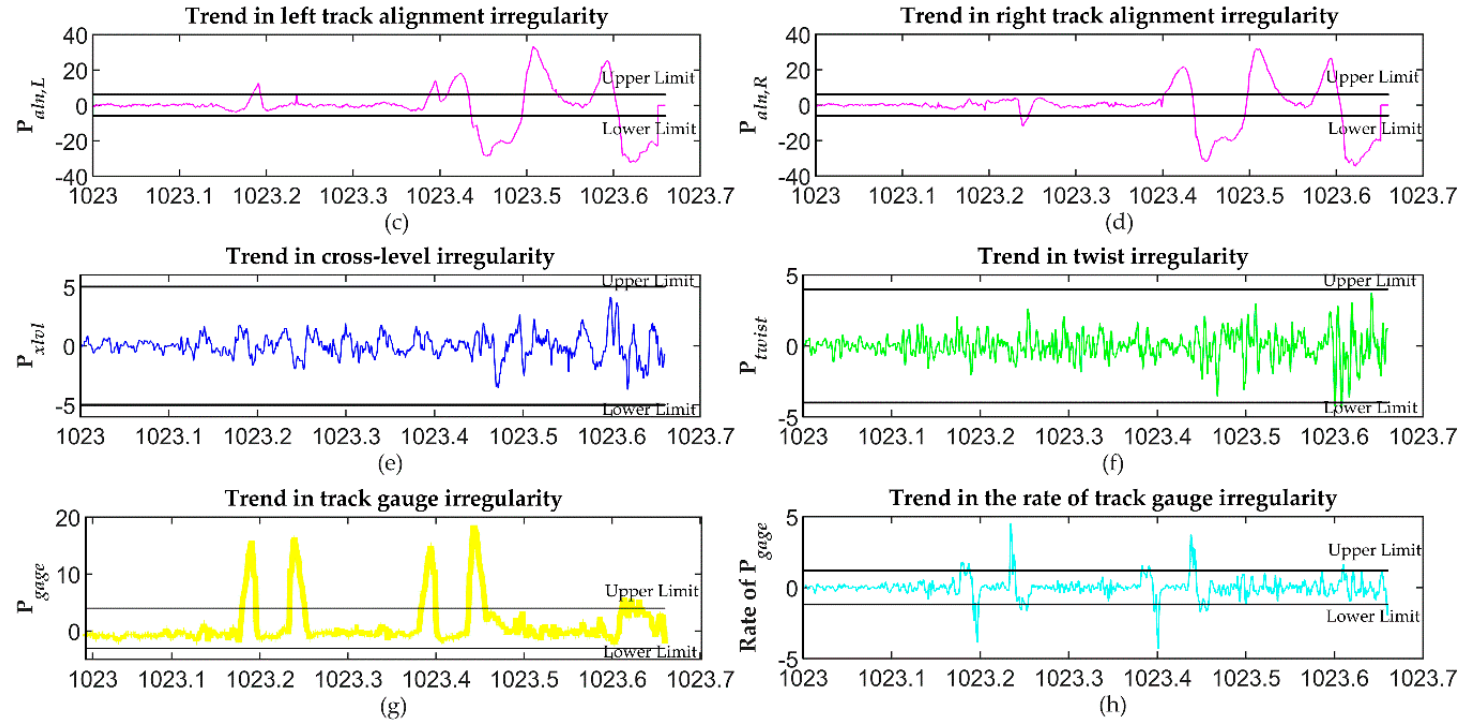

Figure 3. Trend in the geometric parameters from K1023 to K1024 (unit: km): (a) Left surface irregularity, (b) right surface irregularity, (c) left track alignment irregularity, (d) right track alignment irregularity, (e) cross-level irregularity, (f) twist irregularity, (g) track gauge irregularity, and (h) the rate of track gauge irregularity.

Figure 3 shows the variation in each geometrical parameter between K1023 and K1024. The values of $\mathrm{P}_{p r f, L}$ and $\mathrm{P}_{p r f, R}$ exceeded the upper and lower limits between K1023.6 K1023.7, as shown in Figure 3a,b. $\mathrm{P}_{a l n, L}$ and $\mathrm{P}_{a l n, R}$ between K1023.4 K1023.6 exhibited significant fluctuations and exceeded the upper and lower limits at some positions, as shown in Figure 3c,d. This had a substantial impact on passenger comfort and should be considered a risk for the high-speed track. Such risk is also noticeable in Figure $3 \mathrm{~g}, \mathrm{~h}$. Figure $3 \mathrm{e}, \mathrm{f}$ show that the values of $\mathrm{P}_{x l v l}$ and $\mathrm{P}_{\text {twist }}$ were below the lower limit. Therefore, as a whole, this section of the track was risky. The TQI in Figure 2 did not exceed the management value, at $8 \mathrm{~mm}$. This leads to inaccurate risk judgment. The time factor-based DCE can clearly show the obvious risk. Moreover, it can also indicate the potential risk, as illustrated in Figures 4 and 5. 

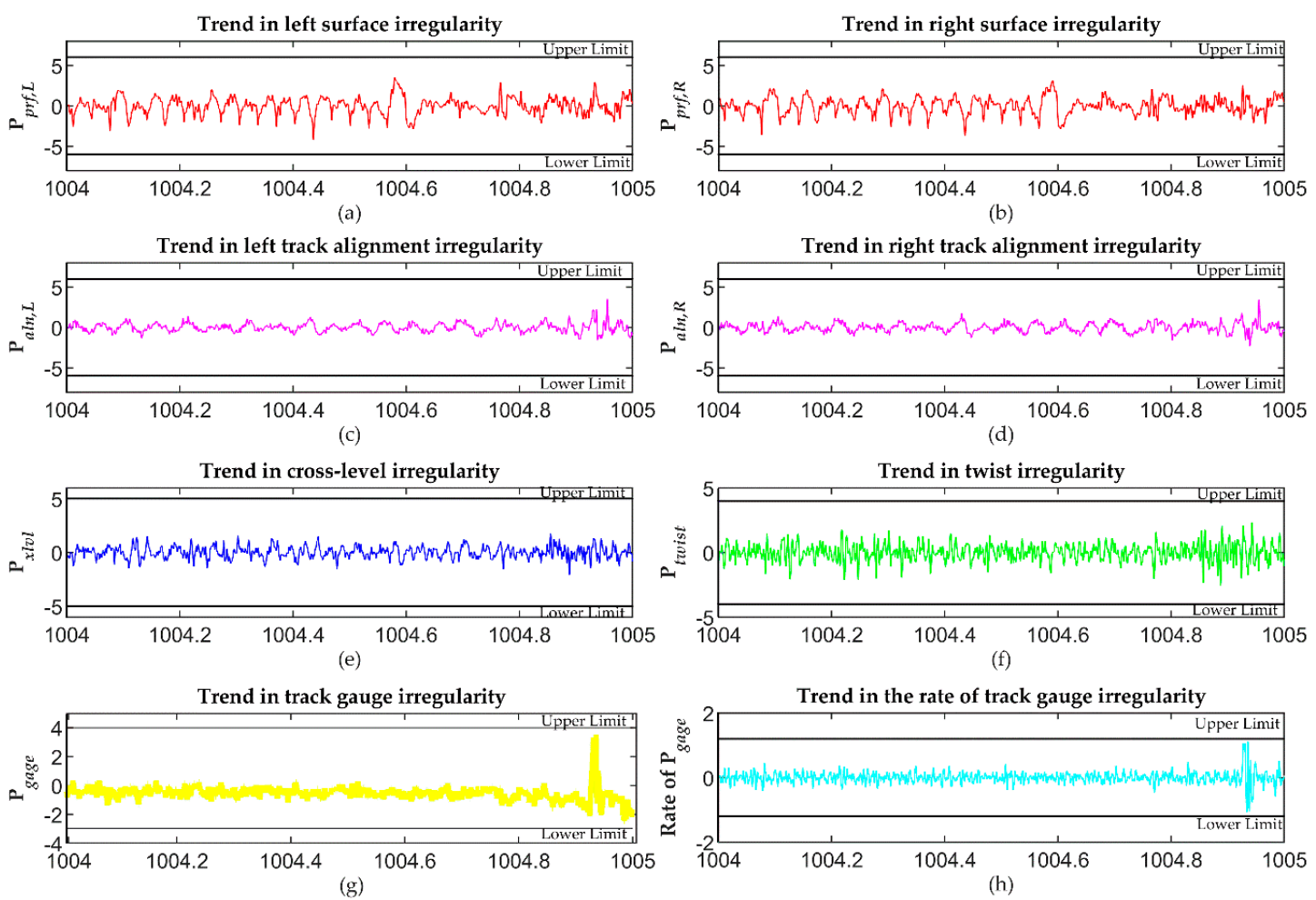

Figure 4. Trends in the geometric parameters from K1004 to K1005 (unit: km): (a) Left surface irregularity, (b) right surface irregularity, (c) left track alignment irregularity, (d) right track alignment irregularity, (e) cross-level irregularity, (f) twist irregularity, (g) track gauge irregularity, and (h) the rate of track gauge irregularity.
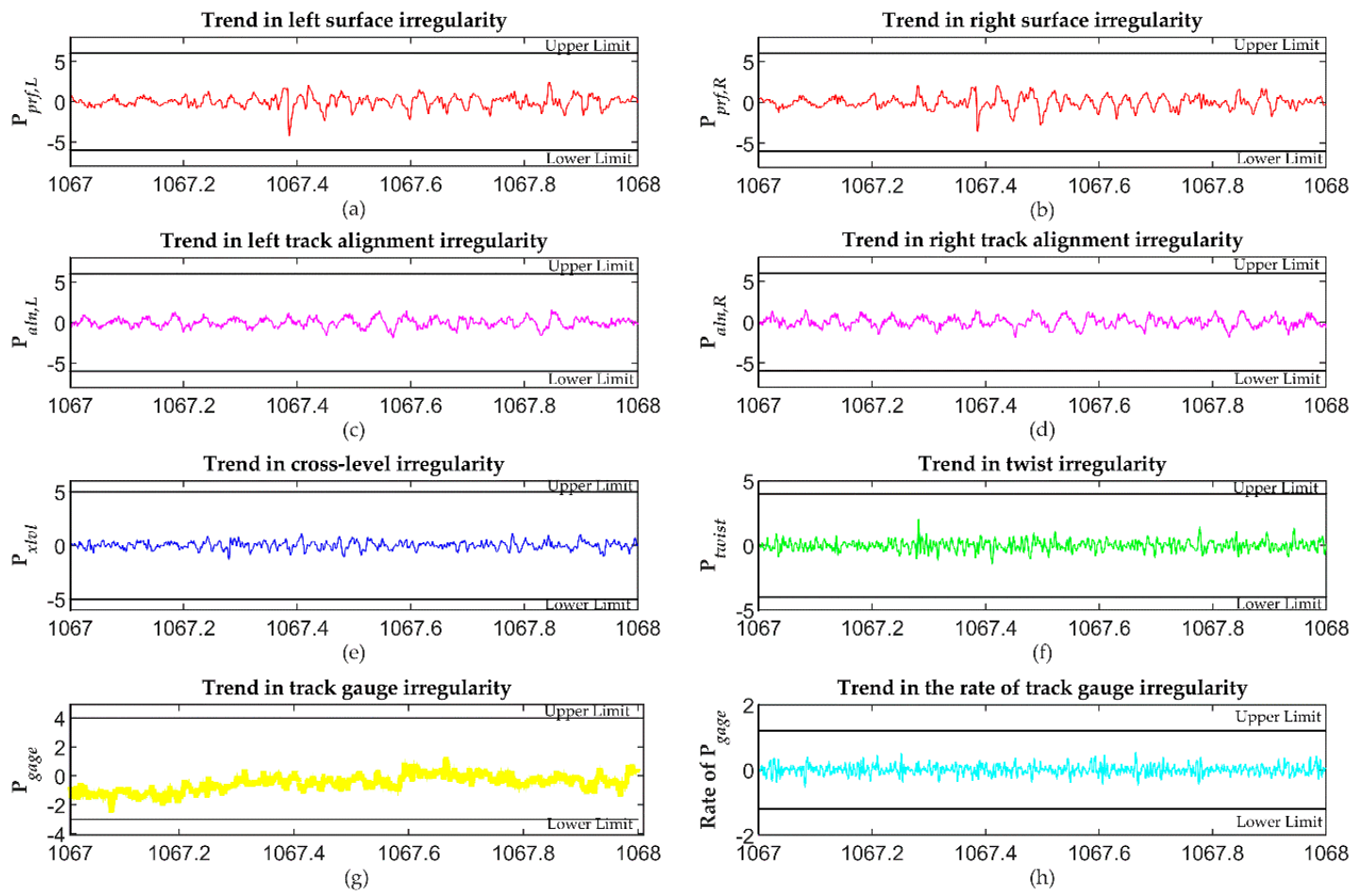

Figure 5. Trend in the geometric parameters from K1067 to K1068 (unit: km): (a) Left surface irregularity, (b) right surface irregularity, (c) left track alignment irregularity, (d) right track alignment irregularity, (e) cross-level irregularity, (f) twist irregularity, (g) track gauge irregularity, and (h) the rate of track gauge irregularity. 
Table 14. Peak management standard-I levels for the geometric parameter for the speed of $200 \sim 250 \mathrm{~km} / \mathrm{h}$.

\begin{tabular}{lcccccc}
\hline Parameters & $\mathbf{P}_{\text {aln }}$ & $\mathbf{P}_{\text {prf }}$ & $\mathbf{P}_{\text {xlvl }}$ & $\mathbf{P}_{\text {gage }}$ & $\mathbf{P}_{\text {twist }}$ & Rate of $\mathbf{P}_{\text {gage }}$ \\
\hline value & 6 & 6 & 5 & $\begin{array}{c}+4 \\
-3\end{array}$ & 4 & 1.2 \\
\hline
\end{tabular}

It is clear from Figures 4 and 5 that all the parameters did not exceed the management values. However, the twist and gage rate were very close to the upper and lower limits (see Table 14) on the segment from K1004.9 to K1005, as shown in Figure 4g,h, indicating potential risk. The fluctuations in $\mathrm{P}_{p r f, L}$ and $\mathrm{P}_{p r f, R}$ imply that the section was dangerous. Another potential risk can be identified from the trend lines of $\mathrm{P}_{p r f, L}, \mathrm{P}_{p r f, R}$, and $\mathrm{P}_{\text {gage, }}$, which are shown in Figure $5 \mathrm{a}, \mathrm{b}, \mathrm{g}$. The minimums of $\mathrm{P}_{p r f, L}$ and $\mathrm{P}_{p r f, R}$ were close to the limit value on the section between 1067.3 and 1067.4, while the minimum of $\mathrm{P}_{\text {gage }}$ was close to the limit value on the section between 1067 and 1067.2. The peaks and valleys of the curves in Figures 4 and 5 did not exceed the limit values, but significant fluctuations appeared. This indicates that the section may have been deteriorating, which is dangerous.

All the trend lines in Figures 3-5, especially Figure 3, had an apparent peak and valley. Meanwhile, Figure 3 contains parameter values exceeding the limits, which indicate obvious risk. In Figures 4 and 5 , some parameters had values very close to the limits, which suggest potential risks. These potential risks could not be identified in Figure 1, confirming that the incentive factor-based DCE method is much more accurate in identifying the risky sections than the TQI method. The results can be used by rail administrations for safety control and track maintenance, inspection, and rehabilitation.

\section{Conclusions}

TQI is the primary method for comprehensive evaluation of high-speed railway tracks. The methods used to calculate TQI vary from country to country. In China, TQI is calculated as the sum of the standard deviations of seven common track geometry measures. This method is described in detail in the third section. In the U.S., TQI is calculated as the ratio of the traced space curve length to the track segment length [10]. Other computing modes used in a different country can be found in reference [6]. TQI assesses the average quality to track segments using statistical characteristic value, and it is also the key index to evaluate the state of track geometry. This method can reveal the degree of smoothness of track and the position of obvious risk to some extent. However, some potential risks cannot be reflected because the collection of basic data is lagging. In other words, the track geometric parameters have not reached the peak level or just reached the limit when the scene changes have taken place on a large scale. The hysteresis in peak management is very dangerous.

In this paper, in order to ensure timely detection of track disease in its early stages of development, an incentive factor-based DCE method was introduced to evaluate the geometric parameters of high-speed tracks. Furthermore, the AHP-entropy method was used to determine the weights of geometric parameters based on the correlation coefficients between parameters. This step was essential to highlight the influence of different parameters on TQI. In the case study, the proposed method revealed one obvious risk and two potential risks in the test section (Figures 3-5). The geometrical parameters between K1023 and K1024 showed significant fluctuations, with some values exceeding the upper and lower limits (Figure 3). This suggests that the section needed to be repaired. The values of geometrical parameters shown in Figures 4 and 5 were within the limit ranges, but the twist $\mathrm{P}_{\text {twist }}$ and gage rate Figure 4 and $\mathrm{P}_{p r f, L}, \mathrm{P}_{p r f, R}$, and $\mathrm{P}_{\text {gage }}$ in Figure 5 were very close to the limit values. So, this section needed to be closely watched or maintained. The results also prove the DCE is more effective in risk identification. Based on the findings of the study, proper maintenance guidelines can be made.

Based on the research work presented in this paper, we can further develop the proposed method by introducing more sensitivity indexes. This paper only considered the geometric parameters, but other parameters exist affecting high-speed tracks, such as acceleration parameters. These also 
play an essential role in evaluating the risk in the high-speed track industry. In addition, there is a hidden relationship between these parameters and railway structural. For example, the settlement of high-speed railway subgrade may be the main reason for the fluctuations in $\mathrm{P}_{p r f, L}$ and $\mathrm{P}_{p r f, R}$, shown in Figure 2. Therefore, it is essential to study these hidden reasons. We hope to continue this work and develop the DCE method further.

Author Contributions: Conceptualization, X.W.; Methodology, X.W.; Software, X.W. and J.W.; Validation, J.Y., Y.W. and G.X.; Formal analysis, X.W.; investigation, X.W. and G.X.; Resources, J.Y. and G.X.; Data curation, X.W.; Writing-original draft preparation, X.W.; Writing—review and editing, X.W. and J.W.; Visualization, J.W.; Supervision, J.Y. and Y.W.; Project administration, X.W. and J.W.; Funding acquisition, X.W. All authors have read and agreed to the published version of the manuscript.

Funding: This research was funded by National Natural Science Foundation of China, grant number 51975038; Besides, this research was also funded by Natural Science Foundation of Beijing Municipal, grant number KZ202010016025.

Conflicts of Interest: The authors declare no conflict of interest.

\section{References}

1. Chen, X.; Wang, L.; Tao, X.; Cui, G.; Yang, F.; Chai, X.; Wu, W. Study on the Judgment Method for Track Regularity of the Main Railway Lines in China. China Railw. Sci. 2008, $29,4$.

2. Berggren, E.G.; Li, M.X.D.; Spnnar, J. A New Approach to the Analysis and Presentation of Vertical Track Geometry Quality and Rail Roughness. Wear 2008, 265, 1488-1496. [CrossRef]

3. Li, M.X.D.; Berggren, E.G.; Berg, M. Assessment of Vertical Track Geometry Quality Based on Simulations of Dynamic Track-Vehicle Interaction. Proc. Inst. Mech. Eng. 2008, 223, 131-139. [CrossRef]

4. Sadeghi, J.M.; Askarinejad, H. Development of Track Condition Assessment Model Based on Visual Inspection. Struct. Infrastruct. Eng. 2011, 7, 895-905. [CrossRef]

5. Sadeghi, J.; Askarinejad, H. Quality Condition Assessment and Determination of Effective Maintenance Activities in Railway Slab Tracks. Int. J. Pavement Eng. 2012, 13, 1-10. [CrossRef]

6. Berawi, A.R.B.; Delgado, R.; Calçada, R.; Vale, C. Evaluation Track Geometrical Quality Through Different Methodologies. Int. J. Technol. 2010, 1, 38-47. [CrossRef]

7. Tan, S.; Mao, X. Research on Transfer Matrix Between Dynamic and Static Track Quality Index in Newly-Build Ballastless Track of High-Speed Railway. J. Railw. Sci. Eng. 2016, 13, 1674-1680.

8. Li, G. Research on The Track Quality Index and Its Application in High Speed Railway Dynamic Acceptance. J. Railw. Sci. Eng. Soc. 2016, 33, 45-50.

9. Lv, X. Study on Construction Risk Assessment of Newly-Built Railway Under Bridges with Existing High-Speed. Master's Thesis, Southwest Jiaotong Universtity, Chengdu, China, 2018.

10. Sharma, S.; Cui, Y.; He, Q.; Mohammadi, R.; Li, Z. Data-Driven Optimization of Railway Maintenance For Track Geometry. Transp. Res. Part C Emerg. Technol. 2018, 90, 34-58. [CrossRef]

11. Ma, S.; Gao, L.; Liu, X.; Lin, J. Deep Learning For Track Quality Evaluation of High-Speed Railway Based on Vehicle-Body Vibration Prediction. IEEE Access 2019, 7, 185099-185107. [CrossRef]

12. Qian, J.; Yi, J.; Zhang, J.; Cheng, Y.; Liu, J. An Entropy Weight-Based Lower Confidence Bounding Optimization Approach For Engineering Product Design. Appl. Sci. 2020, 10, 3554. [CrossRef]

13. Dao, M.; Nguyen, A.; Nguyen, T.; Pham, H.; Nguyen, D.; Tran, Q.; Dao, H.; Nguyen, D.; Dang, H.; Hens, L. A Hybrid Approach Using Fuzzy Ahp-Topsis Assessing Environmental Conflicts in the Titan Mining Industry Along Central Coast Vietnam. Appl. Sci. 2019, 9, 2930. [CrossRef]

14. Yuanyuan, S.; Gang, Z.; Bo, A.; Zhangdui, Z. Interference Assessment in the High-Speed Railway Wireless Communication Networks By Ahp-Grap. In Proceedings of the 2013 Fifth International Conference on Measuring Technology and Mechatronics Automation(Icmtma 2013), Hong Kong, China, 16-17 January 2013; pp. 654-662.

15. Saaty, T.L. Axiomatic Foundation of the Analytic Hierarchy Process. Manag. Sci. 1986, 32, 841-855. [CrossRef]

16. Charnes, A.; Cooper, W.W.; Rhodes, E. A Data Envelopment Analysis Approach to Evaluation of the Program Follow through Experiment in U.S. Public School Education; Carnegie-Mellon Univ Pittsburgh Pa Management Sciences Research Group: Pittsburgh, PA, USA, 1978; pp. 1-64. 
17. Leitner, K.H.; Marr, B.; Schaffhauser-Linzatti, M.; Stowasser, R.; Wagner, K. Data Envelopment Analysis As Method For Evaluating Intellectual Capital. J. Intellect. Cap. 2005, 6, 528-543. [CrossRef]

18. Rotoli, F.; Navajas Cawood, E.; Christidis, P. A Data Envelopment Analysis Approach for Accessibility Measures: Simulating Operational Enhancement Scenarios for Railway Across Europe. Eur. Transp. Res. Rev. 2015, 7, 18. [CrossRef]

19. Haeri, H.; Xu, D.R.; Gang, J.; Gan, L.; Li, Z.Q. Economic Evaluation of Renewable Energy Saving Technology Based on Analytic Hierarchy Process and Data Envelopment Analysis Method. In Materials in Environmental Engineering; De Gruyter: Berlin, Germany, 2017. [CrossRef]

20. Du, D.; Pang, Q.; Wu, Y. Modern Comprehensive Evaluation Method and Case Selection; Tsinghua University Press: Beijing, China, 2015; ISBN 978-302-42372-0.

21. Zhang, F.-M.; Liu, Z.P. Combined Evaluation Methods: A Literature Review. J. Syst. Eng. 2017, 32, 557-569.

22. Guo, Y. Comprehensive Evaluationtheory, Method and Application; China Science Publishing \& Media Ltd.(Cspm): Beijing, China, 2007; ISBN 978-7-03-018796-3.

23. Xu, A.; Zhang, J.; Li, M. Comprehensive Evaluation Model of Livable City Based on Fuzzy Comprehensive Evaluation Metho. Asian Agric. Res. 2018, 10, 65-69.

24. Xie, N.; Yang, Y.; Mi, C.; Guo, S.D.; Liu, S.; Fang, Z.; Wang, L. Multi-Phase Information Aggregation and Dynamic Synthetic Evaluation Based on Grey Inspiriting Control Lines. Grey Syst. Theory Appl. 2014, 4, 154-163. [CrossRef]

25. Ma, Z.F.; Guo, Y.J.; Zhang, F.M.; Pan, Y.H. Method of Dynamic Comprehensive Evalution Based on Gain Level Inspiriting. J. Syst. Eng. 2009, 24, 223-247. [CrossRef]

26. Zhang, F.M.; Sun, W.L. Improved Dynamic Incentive Comprehensive Evalution Method and Its Application. J. Syst. Eng. 2015, 30, 711-718.

27. Zhang, F.M. Dynamic Comprehensive Evalution Method Based on Double Incentives Model and Its Application. J. Syst. Eng. 2013, 28, 248-255.

28. Zhang, F.M. Research on a Dynamic Credit Evalution Method Integration Som and K-Means Clustering Algorithm. J. Syst. Eng. 2014, 23, 186-192.

29. Dongri, H.; Li, T.; Shi, Z.; Feng, S. Research on Dynamic Comprehensive Evaluation of Resource Allocation Efficiency of Technology Innovation in the Aerospace Industry. Math. Probl. Eng. 2020, 2020, 8421495. [CrossRef]

30. Ministry of Railways of the People's Republic of China. Transmission Line [2009] 41. Standards for Quality INDEX of Irregularity of Existing Railway Tracks and Interim Measures for Management; Traffic Department: Beijing, China, 2009.

31. Fazio, A.E.; Corbin, J.L. Track Quality Index for High Speed Track. J. Transp. Eng. 1986, 112, 46-61. [CrossRef]

32. Jadidirendi, K.; Zakeri, J.A.; Teng, H.H. Field Investigation for Identifying the Effects of Dynamic Track Stabilizing Operation on Track Geometrical Indices. In ASME/IEEE Joint Rail Conference; American Society of Mechanical Engineers: New York, NY, USA, 2015; pp. 1-8. [CrossRef]

33. Ministry of Railways of the People's Republic of China. Rules for Maintenance of Ballastless Track of High-Speed Railway (Trial). Natl. Railw. Adm. Repub. China. 2012; pp. 59-65. Available online: http://www.nra.gov.cn/jgzf/flfg/gfxwj/zt/other/201803/t20180321_54084.shtml (accessed on 3 June 2020).

34. Bai, L.; Liu, R.; Sun, Q.; Wang, F.; Xu, P. Markov-Based Model for the Prediction of Railway Track Irregularities. Rail Rapid Transit 2015, 229, 150-159. [CrossRef]

35. Sharma, J. Economics of Decision Making: Exploring Analytical Hierarchical Process (Ahp). Theor. Econ. Lett. 2018, 8. [CrossRef]

36. Chen, Z.M.; Yeh, Y.L.; Chen, T.C. Assessment of a Regional Flood Disaster Indicator Via An Entropy Weighting Method. Nat. Hazards Rev. 2018, 19. [CrossRef]

37. Zhu, Y.; Tian, D.; Yan, F. Effectiveness of Entropy Weight Method in Decision-Making. Math. Probl. Eng. 2020, 2020, 1-5. [CrossRef]

(C) 2020 by the authors. Licensee MDPI, Basel, Switzerland. This article is an open access article distributed under the terms and conditions of the Creative Commons Attribution (CC BY) license (http://creativecommons.org/licenses/by/4.0/). 